\title{
GEOLOGIA E GEOCRONOLOGIA DOS GRANITÓIDES ARQUEANOS DA REGIÃO DE XINGUARA-PA E SUAS IMPLICAÇÕES NA EVOLUÇÃO DO TERRENO GRANITO-GREENSTONE DE RIO MẢRIA, CRÁTON AMAZÔNICO
}

\author{
ALBANO ANTONIO DA SILVA LEITE ${ }^{1,2}$, ROBERTO DALL'AGNOL ${ }^{1}$, MOACIR JOSÉ \\ BUENANO MACAMBIRA ${ }^{4}$ \& FERNANDO JACQUES ALTHOFF ${ }^{1,3}$
}

\begin{abstract}
GEOLOGYAND GEOCHRONOLOGY OF ARCHEAN GRANITOIDS OF THE XINGUARA REGION: IMPLICATIONS FOR THE EVOLUTION OF THE RIO MARIA GRANITE-GREENSTONE TERRANE, AMAZONIAN CRATON The Xinguara area, located in the Rio Maria Granite-Greenstone Terrain - Pará, is composed of several Archaean granitoids. Structures and fabric elements visible at outcrop and microscopic scales, and zircon $\mathrm{Pb}-\mathrm{Pb}$ ages suggest that these granitoids were emplaced in two distinct episodes of growth of the Archaean crust: (i) $2.948 \pm 5$ to $2.924 \pm 2 \mathrm{Ma}$, genesis, emplacement and deformation of Caracol tonalitic complex, related to Arco Verde tonalite, wich outcrops in Marajoara area, and to TTG rocks of the São Félix do Xingu region. This period was marked by the formation of thick greenstone sequences and TTG plutons, forming dome-and-keel structures, related to a vertical tectonics, like those reported in the east Pilbara (Autralia) and Dharwar (India) cratons; (ii) $2.878 \pm 4$ to $2.865 \pm 1 \mathrm{Ma}$, genesis, emplacement and deformation of the Rio Maria granodiorite, Água Fria trodhjemite and Xinguara granite. In this period, some $50 \mathrm{Ma}$ after formation of the last TTG, distinct magmatic series were formed in a short time span (10-15 Ma). In this stage, plate convergence and subduction processes were operative.
\end{abstract}

Keyworks: TTG Archean granitoids, leucogranites, $\mathrm{Pb}-\mathrm{Pb}$ zircon geochronoloogy, Carajás Mineral Province, Rio Maria GraniteGreenstone Terrane, Amazonian Craton.

Resumo A região de Xinguara, no Terreno Granito-Greenstone de Rio Maria - PA, é composta por vários tipos de rochas granitóides arqueanas. Relações de campo e dados isotópicos $\mathrm{Pb}-\mathrm{Pb}$ por evaporação de zircão indicam que a formação destas rochas ocorreu em dois períodos principais, com características tectônicas distintas: (i) $2.948 \pm 5$ a $2.924 \pm 2$ Ma, geração, colocação e deformação do Tonalito Caracol, correlacionado ao Tonalito Arco Verde, da região de Marajoara, e aos granitóides TTG da região de São Félix do Xingu. Este período foi marcado pela formação de um terreno à base de domos TTG e bacias de greenstone belts associado a uma tectônica vertical, similar aos dos crátons Pilbara (Austrália) e Dharwar (Índia); (ii) $2.878 \pm 4$ a $2.865 \pm 1$ Ma, geração, colocação e deformação do Granodiorito Rio Maria, Trondhjemito Água Fria e do Granito Xinguara. Neste período, que ocorreu cerca de 50 Ma após a formação dos últimos granitóides TTG, formaram-se vários granitóides geneticamente diferentes em um curto espaço de tempo (10-15 Ma). Nesta etapa, o processo de convergência e subducção de placas parece ter sido mais efetivo.

Palavras-chave: granitóides arqueanos TTG, leucogranitos, geocronologia Pb-Pb em zircão, Província Mineral de Carajás, Terreno Granito-Greenstone de Rio Maria, Cráton Amazônico.

INTRODUÇÃO A Província Mineral de Carajás situa-se na porção oriental do Cráton Amazônico, SE do estado do Pará (Fig. 1). Em virtude das suas inúmeras riquezas minerais, tornou-se uma das regiões melhor estudadas da Amazônia. No entanto, nesta província existem algumas porções onde trabalhos de mapeamentos geológicos e estudos de metalogênese e geocronologia são raros, ou ainda não foram executados, o que dificulta bastante a elaboração de um quadro geológico regional.

A região de Xinguara, área abordada no presente trabalho (Fig. 1), situa-se no limite entre o Terreno Granito-Greenstone de Rio Maria e o Cinturão de Cisalhamento Itacaiúnas. O quadro estratigráfico do Terreno Granito-Greenstone de Rio Maria vem sendo progressivamente melhor definido, tendo em vista os inúmeros trabalhos de mapeamento geológico executados pela Docegeo/CVRD e a CPRM na década de 80 e início de 90 . Uma contribuição significativa vem sendo dada pelos pesquisadores do Laboratório de Geologia Isotópica do CG-UFPA, mediante datações por métodos geocronológicos mais precisos $(\mathrm{Pb}-\mathrm{Pb}$ em zircão e SHRIMP). O Grupo de Pesquisa Petrologia de Granitóides do CG/UFPA também tem dado sua contribuição por mapeamentos geológicos de semi-detalhe, estudos petrográficos, geoquímicos e estruturais e, mais recentemente, em colaboração com pesquisadores do Laboratório de Geologia Isotópica do CG-UFPA, também nos estudos geocronológicos.

$\mathrm{O}$ método de datação por evaporação direta de $\mathrm{Pb}$ em monocristais de zircão é uma ferramenta apropriada para a determinação da idade de cristalização de rochas antigas. No presente trabalho, este método foi aplicado em algumas amostras de rochas granitóides da região de Xinguara, com o objetivo primordial de definir as idades das mesmas, contribuindo para uma melhor definição do quadro estratigráfico local e, permitindo assim, estabelecer uma correlação direta com os demais granitóides do Terreno Granito-Greenstone de Rio Maria e com os eventos termotectônicos que ocorreram na Província Mineral de Carajás.

1 - Grupo de Pesquisa Petrologia de Granitóides - Universidade Federal do Pará, CG, C.P. 1611, 66075-900, Guamá - Belém-PA. E-mails: albano.leite@cvrd.com.br, robdal@ufpa.br

2 - Companhia Vale do Rio Doce - Rod. 263, km 296, 33030-970, Santa Luzia-MG. E-mail: albano.leite@cvrd.com.br

3 - Universidade Vale do Rio dos Sinos, Av. Unisinos, 950, 93022-000, São Leopoldo-RS. E-mail: althoff@euler.unisinos.br

4 - Laboratório de Geologia Isotópica - Universidade Federal do Pará, CG, C.P. 1611, 66075-900, Guamá - Belém-PA. E-mail: moamac@ufpa.br 
GRANITÓIDES DA PROVÍNCIA MINERAL DE CARAJÁSSÍNTESE DOS DADOS GEOLÓGICOS E GEOCRONOLÓ-

GICOS A Província Mineral de Carajás possui idade arqueana, como atestam vários dados geocronológicos (Fig. 1, Tabela 1). Costa et al. (1995) distinguiram nesta região três domínios tectônicos: Terreno Granito-Greenstone de Rio Maria, limitado a norte e a sul pelos cinturões de cisalhamento Itacaiúnas e Pau D'Arco, respectivamente. Entretanto, Althoff et al. (1995) e Dall'Agnol et al. (1997) não consideram a existência do Cinturão de Cisalhamento Pau D'Arco, não havendo aí, um domínio tectônico distinto e sim uma extensão para sul do Terreno GranitoGreenstone de Rio Maria, que se prolongaria pelo menos até a cidade de Redenção.

Souza et al. (1996) subdividem a Província Mineral de Carajás em dois domínios tectônicos: Terreno Granito-Greenstone de Rio Maria e o Bloco Carajás. Segundo estes autores, o limite entre este domínios, que corresponderia à porção norte do Cinturão de Cisalhamento Itacaiúnas não é claro, podendo estar situado imediatamente a sul do Granito Xinguara ou a norte do Greenstone Belt da Sapucaia. Dall'Agnol et al. (1997) sugerem que a região entre Xinguara e o sul da Serra dos Carajás, embora pertencente ao Terreno Granito-Greenstone de Rio Maria, seria uma zona de transição, pois foi afetada pelos eventos atuantes no Bloco Carajás.

A estratigrafia e as principais unidades da Província Mineral de Carajás constam da figura 1 e Tabela 1. Dall'Agnol et al. (1997) com base em dados petrográficos, geoquímicos e geocronológicos dividiram os granitóides da Província em sete grupos. Os cinco primeiros têm idades arqueanas (3,0 a 2,5 Ga, Tabela 1), e os dois últimos paleoproterozóicas $(1,95$ a 1,86 Ga). Os três grupos mais antigos pertencem ao Terreno Granito-Greenstone de Rio Maria (Fig. 1): 1 - tonalito-trondhjemito-granodioritos de suítes tipo TTG; 2 - granitóides ricos em Mg, tipo Granodiorito Rio Maria; 3 -

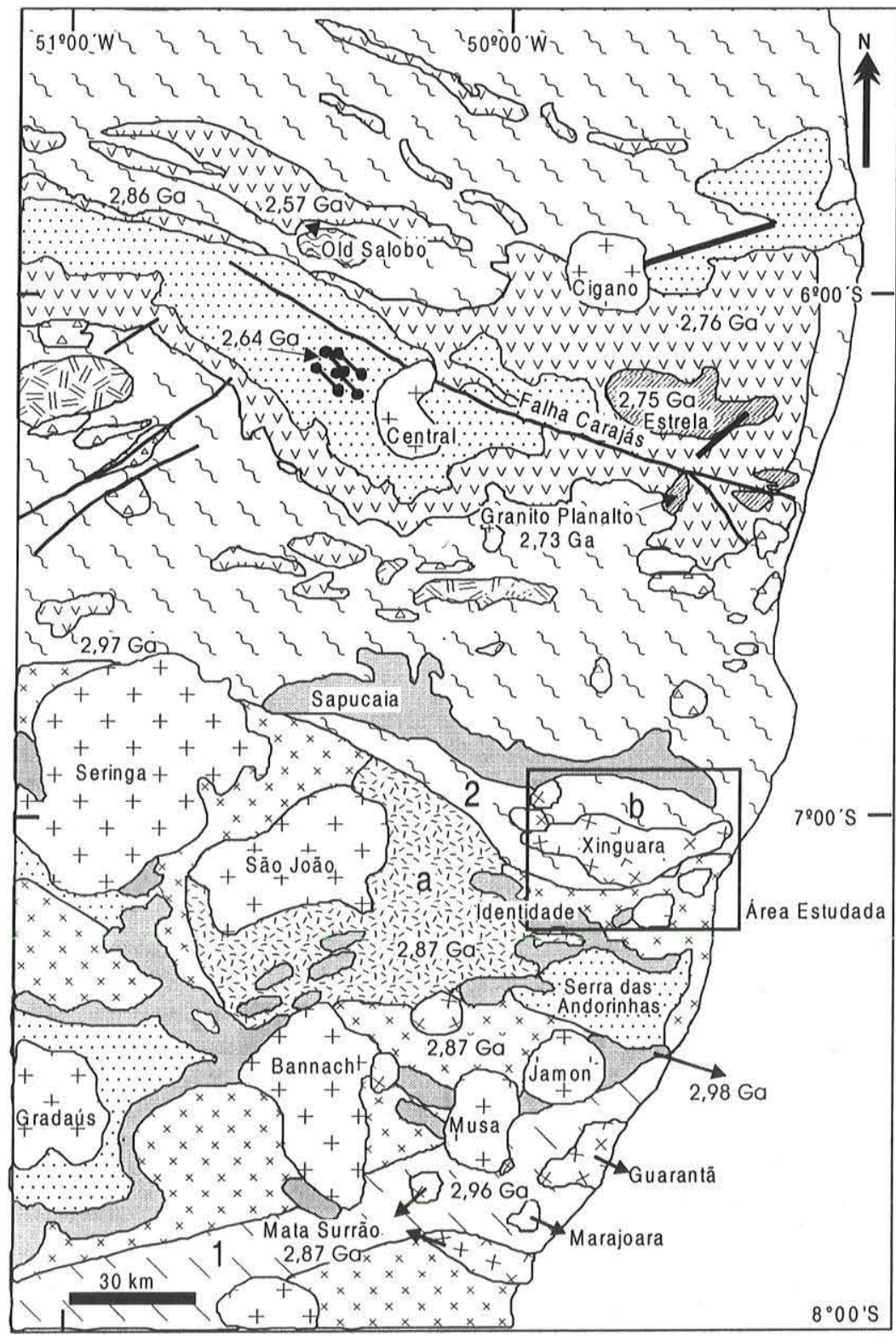

\section{Arqueano}

Granitos Alcalinos Grupo Rio Fresco/ Formação Águas Claras Supergrupo Itacaiúnas Suite Plaquê Leucogranitos a - Trondhjemito Mogno, b - Trondhjemito Água Fria Granodiorito Rio Maria Granitóides TTG: 1 - Tonalito Arco Verde, 2 - Complexo Tonalítico Caracol Complexo Xingu

Greenstone Belts Complexo Pium

Neoproterozóico Cinturão Araguaia

Paleoproterozóico

Granitos Anorogênicos

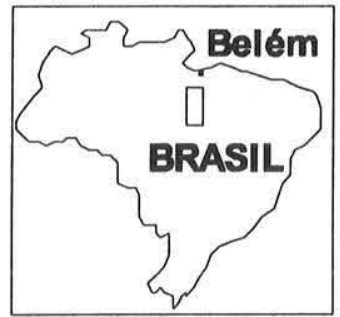

Figura 1-Mapa geológico simplificado da Província Mineral de Carajás (modificado de Docegeo 1988). 
Tabela I - Dados geocronológicos das rochas arqueanas da Província Mineral de Carajás.

\begin{tabular}{|c|c|c|c|c|}
\hline Unidades Estratigráficas & Tipo de Rocha & Método & $\begin{array}{c}\text { Material } \\
\text { Analisado }\end{array}$ & $\begin{array}{l}\text { Idade(Ma)l } \\
\text { Referência }\end{array}$ \\
\hline \multicolumn{5}{|c|}{ REGIÄO DE CARAJÁS } \\
\hline Complexo Pium & \begin{tabular}{|l|} 
Granulito \\
Granulito \\
Granulito \\
\end{tabular} & $\begin{array}{c}\mathrm{Pb}-\mathrm{Pb} \\
\text { SHRIMP } \\
\text { SHRIMP } \\
\end{array}$ & $\begin{array}{l}\text { Rocha total } \\
\text { Zircão } \\
\text { Zircão } \\
\end{array}$ & $\begin{array}{c}3.050 \pm 114(1) \\
3.002 \pm 14(2) \\
2.859 \pm 9(2) \\
\end{array}$ \\
\hline Complexo Xingu & $\begin{array}{c}\text { Leucossoma granítico } \\
\text { Gnaisse félsico }\end{array}$ & $\begin{array}{l}\text { U-Pb } \\
\text { U-Pb }\end{array}$ & $\begin{array}{l}\text { Zircão } \\
\text { Zircão } \\
\end{array}$ & $\begin{array}{l}2.859 \pm 2(3) \\
2.851 \pm 4(3) \\
\end{array}$ \\
\hline \multicolumn{5}{|l|}{ Supergrupo Itacaiúnas } \\
\hline Grupo Salobo & $\begin{array}{l}\text { Anfibolito } \\
\text { Anfibolito }\end{array}$ & $\begin{array}{l}\text { U-Pb } \\
\text { U-Pb } \\
\text { U-Pb }\end{array}$ & $\begin{array}{l}\text { Zircão } \\
\text { Titanita } \\
\text { Zircão } \\
\end{array}$ & $\begin{array}{c}2.761 \pm 3(3) \\
2.497 \pm 5(3) \\
2.555+4 /-3(3) \\
\end{array}$ \\
\hline Grupo Igarapé Pojuca & Anfibolito & $\mathrm{U}-\mathrm{Pb}$ & Zircão & $2.732 \pm 2(3)$ \\
\hline Grupo Grão Pará & $\begin{array}{l}\text { Vulcânica félsica } \\
\text { Riolito }\end{array}$ & $\begin{array}{l}\mathrm{U}-\mathrm{Pb} \\
\mathrm{U}-\mathrm{Pb}\end{array}$ & $\begin{array}{l}\text { Zircão } \\
\text { Zircão }\end{array}$ & $\begin{array}{c}2.757 \pm 2(3) \\
2.758 \pm 39(4)\end{array}$ \\
\hline \multicolumn{5}{|l|}{ Granitos Foliados Alcalinos } \\
\hline Granito Itacaiúnas & Granitóide & $\mathrm{Pb}-\mathrm{Pb}$ & Zircão & $2.525 \pm 38(5)$ \\
\hline Granito Old Salobo & Granitóide & $\mathrm{U}-\mathrm{Pb}$ & Zircão & $2.573 \pm 2(3)$ \\
\hline \multirow[t]{2}{*}{ Complexo Granítico Estrela } & Granitóide & $\mathrm{Rb}-\mathrm{Sr}$ & Rocha total & $2.527 \pm 68(6)$ \\
\hline & Granitóide & $\mathrm{Pb}-\mathrm{Pb}$ & Zircão & $2.763 \pm 7(7)$ \\
\hline Metagabros de Águas Claras & \begin{tabular}{|l|} 
Gabro \\
\end{tabular} & $\mathrm{Pb}-\mathrm{Pb}$ & Zircão & $2.645 \pm 12(8)$ \\
\hline \multicolumn{5}{|c|}{ ÁREA DE TRANSIÇÃO ENTRE AS REGIŌES DE RIO MARIA E CARAJÁS } \\
\hline Complexo Xingu & \begin{tabular}{|c|} 
Gnaisse \\
\end{tabular} & $\mathrm{Pb}-\mathrm{Pb}$ & Zircão & $2.972 \pm 16(9)$ \\
\hline Granodiorito Rio Maria & Granitóide & $\mathrm{Pb}-\mathrm{Pb}$ & Zircāo & $2.850 \pm 17(9)$ \\
\hline Suíte Plaquê & Granitóide & $\mathrm{Pb}-\mathrm{Pb}$ & Zircão & $2.729 \pm 29(9)$ \\
\hline Granito Planalto & Granitóide & $\mathrm{Pb}-\mathrm{Pb}$ & Zircão & $2.747 \pm 2(10)$ \\
\hline Intrusivas Dioríticas & \begin{tabular}{|l|} 
Diorito \\
\end{tabular} & $\mathrm{Pb}-\mathrm{Pb}$ & Zircão & $2.738 \pm 6(10)$ \\
\hline \multicolumn{5}{|c|}{ TERRENO GRANITO-GREENSTONE DE RIO MARIA } \\
\hline $\begin{array}{l}\text { Supergrupo Andorinhas } \\
\text { Grupo Lagoa Seca }\end{array}$ & $\begin{array}{l}\text { Metavulcânica félsica } \\
\text { Metavulcânica félsica }\end{array}$ & $\begin{array}{l}\text { U-Pb } \\
\text { U-Pb }\end{array}$ & $\begin{array}{l}\text { Zircão } \\
\text { Zircão } \\
\end{array}$ & $\begin{array}{c}2.904+29 /-22(11) \\
2.979 \pm 5(12)\end{array}$ \\
\hline Identidade & Metadacito & $\mathrm{Pb}-\mathrm{Pb}$ & Rocha total & $2.944 \pm 88(13)$ \\
\hline Tonalito Arco Verde & Tonalito & $\mathrm{U}-\mathrm{Pb}$ & Zircão & $2.957+25 /-21(11)$ \\
\hline Complexo Xingu & Gnaisses Tonalitos & $\mathrm{U}-\mathrm{Pb}$ & Titanita & $2.798 \pm ?(12)$ \\
\hline Granodiorito Rio Maria & $\begin{array}{c}\text { Granodiorito } \\
\text { Granodiorito } \\
\text { Quartzo-diorito }\end{array}$ & $\begin{array}{l}\text { U-Pb } \\
\text { U-Pb } \\
\mathrm{Pb}-\mathrm{Pb}\end{array}$ & $\begin{array}{c}\text { Zircão } \\
\text { Zir, Titan. } \\
\text { Zircão }\end{array}$ & $\begin{array}{c}2.874+9 /-10(11) \\
2.872 \pm 5(12) \\
2.878 \pm 4(14)\end{array}$ \\
\hline Trondhjemito Mogno & Granitóide & $\mathrm{U}-\mathrm{Pb}$ & Titanita & $2.871 \pm ?(12)$ \\
\hline Tonalito Parazônia & Granitóide & $\mathrm{U}-\mathrm{Pb}$ & Titanita & $2.858(12)$ \\
\hline Granodiorito Cumaru & Granitóide & $\mathrm{Pb}-\mathrm{Pb}$ & Zircão & $2.817 \pm 4(15)$ \\
\hline \multirow[t]{2}{*}{ Granito Mata Surrão } & Leucogranito & $\mathrm{Pb}-\mathrm{Pb}$ & Rocha total & $2.872 \pm 10(16)$ \\
\hline & Leucogranito & $\mathrm{Pb}-\mathrm{Pb}$ & Zircão & $2.871 \pm 7(16)$ \\
\hline Granito Guarantã & Leucogranito & $\mathrm{Pb}-\mathrm{Pb}$ & Zircão & $2,93 \mathrm{Ga}(16)$ \\
\hline
\end{tabular}

Fontes: (1) Rodrigues et al. (1992); (2) Pidgeon et al. (2000); (3) Machado et al. (1991); (4) Gibbs et al. (1986); (5) Souza et al. (1995); (6) Barros et al. (1992); (7) Barros et al. (2001); (8) Dias et al. (1996); (9) Avelar et al. (1999); (10) Huhn et al. (1999); (11) Macambira (1992); (12) Pimentel \& Machado (1994); (13) Souza (1994); (14) Dall'Agnol et al. (1999); (15) Lafon et al. (1994); (16) Althoff et al. (2000).

leucogranitos potássicos de afinidade cálcio-alcalina. Os grupos 4 e 5 afloram na região de transição entre Terreno GranitoGreenstone de Rio Maria e o Bloco Carajás e neste último bloco. São representados, respectivamente, pelos granitóides da Suite Plaquê (Araújo et al. 1994), situados na zona de transição e com idade de 2,73 Ga (Avelar et al. 1999); e pelos granitos foliados subalcalinos com idades de 2,52 a 2,76 Ga e representados pelo Complexo Granítico Estrela (Barros et al. 1997), Granito Old Salobo (Lindenmayer et al. 1994), Granito Itacaiúnas (Souza et al. 1995) e 'Granito Planalto (Huhn et al. 1999), todos do Bloco Carajás (Fig. 1, Tabela 1). Os dois grupos de granitos paleoproterozóicos (granitos cálcio-alcalinos de idade entre 2,0 e 1,9 Ga correlacionados à Suite Parauari e granitos anorogênicos com idades em torno de $1,88 \mathrm{Ga}$ ) não serão discutidos nesta síntese.

Os granitóides TTG estão representados pelo Tonalito Arco
Verde (Althoff et al. 2000), granitóides TTG de Xinguara (Leite 2001), Trondhjemito Mogno e Tonalito Parazônia (Huhn et al. 1988), todos expostos no Terreno Granito-Greenstone de Rio Maria. Rochas similares, ainda enquadradas no Complexo Xingu, ocorrem na área de transição entre o Terreno Granito-Greenstone de Rio Maria e o Bloco Carajás, bem como no Bloco Carajás (Fig. 1). Todas estas unidades exibem fortes similaridades petrográficas e geoquímicas, mas suas idades não são totalmente coincidentes. $\mathrm{O}$ Tonalito Arco Verde mostrou uma idade obtida pelo método U-Pb em zircão de 2.957 +25/-21 Ma (Macambira 1992). Idades similares foram obtidas para os granitóides TTG do Complexo Xingu (2.972 $\pm 16 \mathrm{Ma}$, Avelar et al. 1999). O Trondhjemito Mogno datado em $2.871 \mathrm{Ma}$ (U-Pb em titanita, Pimentel \& Machado 1994)é intrusivo no greenstone belt de Identidade (Huhn et al. 1988) e estratigraficamente posterior ao Tonalito Arco Verde. 
O Granodiorito Rio Maria e rochas afins exibem feições petrográficas muito características, facilitando a correlação entre suas diferentes áreas de ocorrência. Eles cobrem uma grande área do Terreno Granito-Greenstone de Rio Maria (Fig. 1), sendo expostos além da sua área tipo (Rio Maria), a sul de Xinguara e a norte de Redenção. Alguns granitóides descritos nas regiões do Xingu e Carajás também são correlacionados ao Granodiorito Rio Maria (Docegeo 1988, Avelar et al. 1999). Rochas máficas e intermediárias, formando enclaves ou pequenos corpos, estão normalmente associadas a ele (Medeiros \& Dall'Agnol 1988, Souza 1994). Rochas do Granodiorito Rio Maria forneceram idades de cristalização de 2.874 +9/-10 Ma (U-Pb em zircão, Macambira 1992), $2.872 \pm$ $5 \mathrm{Ma}$ (U-Pb em zircão e titanita, Pimentel \& Machado 1994) e 2.878 $\pm 4 \mathrm{Ma}$ (Pb-Pb em zircão, Dall'Agnol et al. 1999). Rochas similares que ocorrem na região do Xingu, na área de transição entre o Terreno Granito-Greenstone de Rio Maria e o Bloco Carajás, mostraram idade de $2.850 \pm 17 \mathrm{Ma}$ (Pb-Pb em zircão; Avelar et al. 1999). As relações de campo (Docegeo 1988) mostram que o Granodiorito Rio Maria é intrusivo no Supergrupo Andorinhas.

Leucogranitos potássicos de afinidade cálcio-alcalina são abundantes no Terreno Granito-Greenstone de Rio Maria, representados pelos granitos Xinguara (Leite \& Dall'Agnol 1997), Mata Surrão e Guarantã (Althoff et al. 2000) e por stocks graníticos em contato com o Greenstone Belt Identidade (Souza 1994). O Granito Mata Surrão é intrusivo no Tonalito Arco Verde e em sua área tipo forneceu idade de $2.872 \pm 10 \mathrm{Ma}(\mathrm{Pb}-\mathrm{Pb}$ em rocha total, Macambira \& Lafon 1995). Na região de Marajoara, Althoff $e t$ al. (2000) consideram que o corpo de leucogranito potássico situado imediatamente a sul de Pau D'Arco, inicialmente correlacionado ao Granito Guarantã, possui maiore afinidade geoquímica e geocronológica com o Granito Mata Surrão. Este corpo mostrou idade $\mathrm{Pb}-\mathrm{Pb}$ em zircão de $2.871 \pm 7 \mathrm{Ma}$ (Althoff et al. 2000, Tab. 1). O Granito Guarantã ficou, em função disso, restrito ao corpo localizado a sul do Granito Jamon, com idade de cristalização em $c a$. 2,93 Ga (Althoff et al. 2000). O Granito Xinguara possui enclaves dos granitóides TTG de Xinguara e do Grano-diorito Rio Maria (Leite 2001) e, muito provavelmente, sua idade se situa no intervalo entre 2,87 e 2,80 Ga, definido por Macambira (1992).

Os granitóides da Suíte Plaquê ocorrem na área de transição entre o Terreno Granito-Greenstone de Rio Maria e o Bloco Carajás, na porção sul do Cinturão Cisalhamento Itacaiúnas (Fig. 1). Foram definidos e estudados por Araújo \& Maia (1991) e Araújo et al. (1994). Os granitos da Suíte Plaquê são geralmente foliados e seus contatos com as rochas encaixantes do Complexo Xingu são controlados pelo trend regional E-W (Costa et al. 1995). Uma idade de $2.729 \pm 29 \mathrm{Ma}$ (Pb-Pb em zircão, Avelar et al. 1999) foi obtida para um granito desta suíte e considerada como mínima. Se esta idade corresponder aproximadamente à idade de cristalização da suíte, como ocorre normalmente com outras idades $\mathrm{Pb}-\mathrm{Pb}$ na Província Mineral de Carajás (Macambira \& Lafon 1995), então a Suíte Plaquê é mais jovem do que os granitóides potássicos do Terreno Granito-Greenstone de Rio Maria.

Os granitos foliados subalcalinos do Bloco Carajás são representados pelo Granito Old Salobo (Lindenmayer et al. 1994), Complexo Granítico Estrela (Barros et al. 1997), Granito Planalto (Huhn et al. 1999) e pelos granitóides foliados da região do rio Itacaiúnas (Souza et al. 1995) (Fig. 1). As idades desses granitos estão situadas no intervalo entre 2,76 e 2,52 Ga. O Complexo Granítico Estrela mostra muitas similaridades com o Granito Old Salobo. Ambos são subalcalinos e têm altas razões $\mathrm{Fe} / \mathrm{Mg}$, tanto em rocha total como em minerais. Apesar das similaridades geoquímicas entre o
Granito Old Salobo e o Complexo Granítico Estrela, o último revelou idade $\mathrm{Pb}-\mathrm{Pb}$ em zircão bem maior $(2.763 \pm 7 \mathrm{Ma}$, Barros et al. 2000), demonstrando que não são contemporâneos. Por outro lado, a idade do Complexo Granítico Estrela não é muito distinta das obtidas para a Suíte Plaquê e Granito Planalto (Tab. 1).

\section{ASPECTOSGEOLÓGICOSDOSGRANITÓIDESDA REGIÃO} DEXINGUARA Considerações Gerais O mapeamento geológico executado na região de Xinguara (Leite 2001) revelou a existência de unidades arqueanas e proterozóicas. $\mathrm{O}$ mapa geológico (Fig. 2) apresenta diversas modificações em relação aos divulgados anteriormente (Leite \& Dall'Agnol 1997, Leite et al. 1999).

Os granitóides TTG, enquadrados informalmente por Leite \& Dall'Agnol (1997) nos tonalito-trondhjemitos gnáissicos do Complexo Xingu, foram mais bem definidos por Leite (2001) e Leite $e t$ al. (2001) e formalmente denominados de Tonalito Caracol. Os granitóides trondhjemítico-granodioríticos, identificados inicialmente na porção norte do Granito Xinguara, são denominados de Trondhjemito Água Fria . Este abrange grande parte das porções norte e nordeste da área mapeada, estendendo-se até o limite com o Greenstone Belt de Sapucaia (Fig. 2). Ele é intrusivo na seqüência nas rochas que compõem o Greenstone Belt de Sapucaia e no Tonalito Caracol, pois engloba enclaves dessas unidades. Sua relação com o Granito Xinguara, tal como definida inicialmente por Leite \& Dall'Agnol (1997), é de contemporaneidade, tendo em vista as evidências estruturais e a ausência de enclaves do Trondhjemito Água Fria no Granito Xinguara.

O Granodiorito Rio Maria na região de Xinguara é muito similar, tanto petrográfica como geoquimicamente, ao descrito na área tipo (Medeiros \& Dall'Agnol 1988) e em outras áreas (Souza 1994 Althoff et al. 1995, 2000), justificando plenamente a sua correlação com o mesmo (Leite 2001 e Leite et al. 2001). Seu posicionamento estratigráfico a nível regional é bem definido. É intrusivo nos greenstone belts, no Tonalito Arco Verde e é cortado pelo Trondhjemito Mogno (Huhn et al. 1988, Souza et al. 1990). Na região de Xinguara é intrusivo no Tonalito Caracol, sendo cortado pelo Trondhjemito Água Fria e pelo Granito Xinguara.

Além das unidades mencionadas, há corpos plutônicos, representados pelo Granito Manda Saia, e diques máficos e félsicos, correlacionados ao magmatismo paleoproterozóico presente na região.

Descrição das Unidades Geológicas TONALITO CARACOL Ocorre em três domínios principais na região de Xinguara (Fig. 2). No domínio NW está limitado a norte pelo Greenstone Belt de Sapucaia, a oeste pelo Granodiorito Rio Maria, a leste pelo Trondhjemito Água Fria e a sui pelo Granito Xinguara. Sua estruturação é marcada por um bandamento orientado na direção $\mathrm{N}-\mathrm{S}$, levemente ondulado, com mergulhos fortes a verticais. O bandamento é afetado por bandas de cisalhamento dúctil dextrógiras, orientadas na direção NE-SW. Nas porções SW e sul da área mapeada o Tonalito Caracol ocorre definindo uma faixa orientada na direção NW-SE, sendo limitado a norte pelo Granito Xinguara e Granodiorito Rio Maria e a sul pelo Granodiorito Rio Maria. No domínio SW a estruturação do Tonalito Caracol é marcada por numerosas zonas de cisalhamento de direção NWSE, com mergulhos suaves $\left(20^{\circ}\right)$ para SW. As rochas são marcadas por uma acentuada foliação milonítica, acompanhada de uma lineação mineral subhorizontal que mergulha para NW. No domínio sul domina uma estruturação marcada por um bandamento, similar ao observado no setor $\mathrm{NW}$, porém orientado na direção 


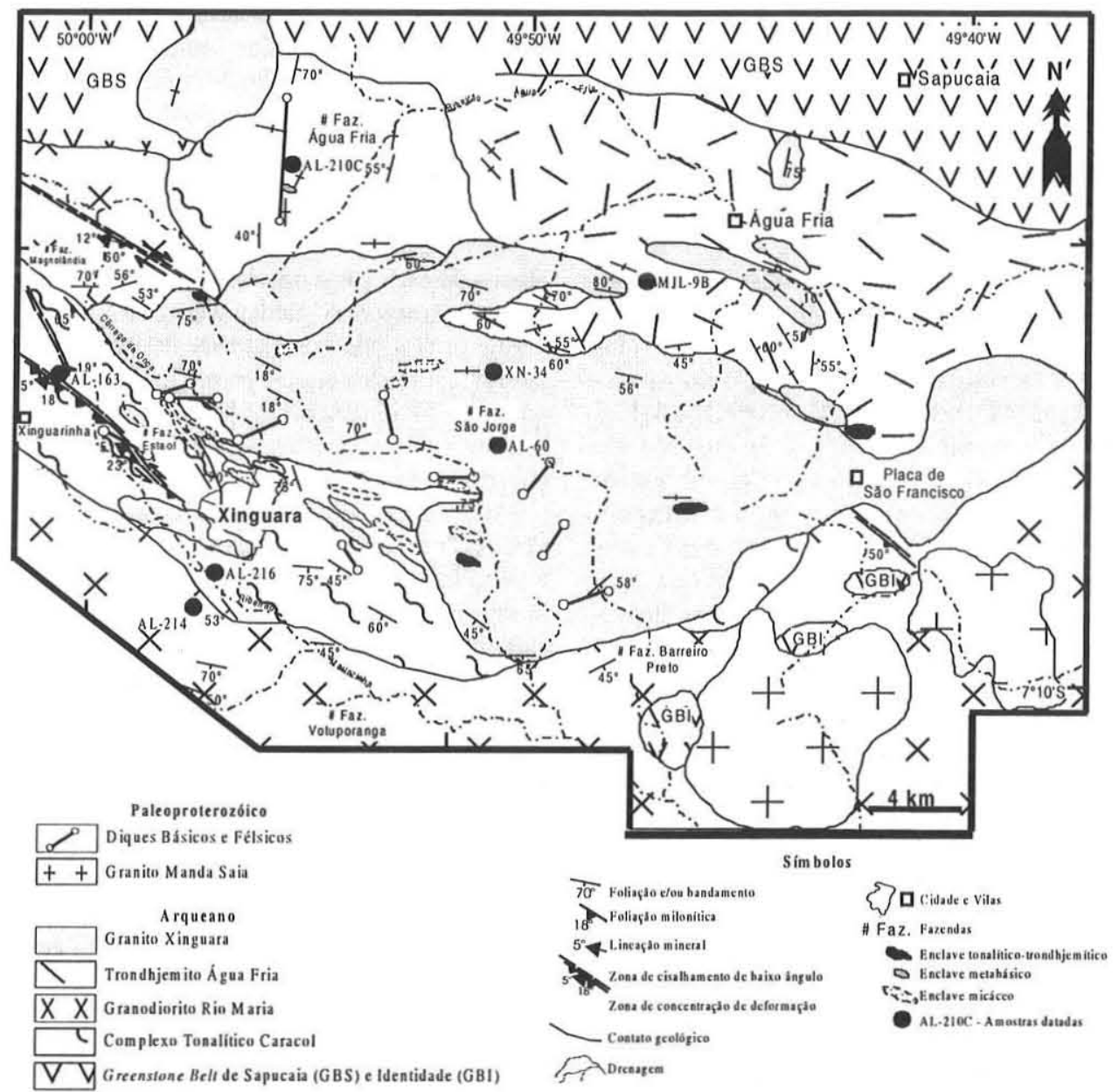

Figura 2 - Mapa geológico da região de Xinguara (Leite 2001).

\section{NW-SEa WNW-ESE.}

GRANODIORITO RIO MARIA Ocorre em grande parte da porção sul da área e em um pequeno corpo aflorante a oeste (Fig. 2). É marcante a sua homogeneidade, verificada tanto por uma textura granular média, quanto pela coloração cinza clara com tons esverdeados, devidas essencialmente aos cristais de plagioclásio saussuritiza-dos. Possui uma foliação paralela à orientação regional NW-SE a WNW-ESE, com mergulho de cerca de $60^{\circ}$ para SW, a qual varia localmente de não penetrativa a penetrativa. Enclaves máficos achatados de tamanhos variados são comuns. Dispõemse paralelamente aos planos da foliação do Granodiorito Rio Maria. Na porção oeste da área, a foliação apresentada pelo Granodiorito Rio Maria acompanha o contorno do Granito Xinguara e seus mergulhos são ora para NW, ora para NE.

TRONDHJEMITO ÁGUA FRIA Aflora por toda porção nordeste da área (Fig. 2). Possui bandamento levemente ondulado, orientado na direção NW-SE a WNW-ESE, com mergulhos subverticais a verticais. Próximo do contato com o Granito Xinguara seus mergulhos são de $60^{\circ}$ para sul e SW, ou para NE (Fig. 2). Contém, localmente, enclaves métricos do Tonalito Caracol. O Trondhjemito Água Fria é cortado por diques e veios leucograníticos relacionados ao Granito Xinguara. Tanto os diques e veios do Granito Xinguara quanto as bandas do Trondhjemito Água Fria encon- tram-se dobrados, indicando um baixo contraste de viscosidade entre ambos quando do dobramento e, provavelmente, uma diferença de idade não muito significativa.

GRANITO XINGUARA Ocupa a parte central da área mapeada. O pluton Xinguara constitui um corpo de forma alongada com eixo maior orientado sub-concordantemente ao trend WNW-ESE regional (Fig. 2). Em termos estruturais, nas variedades mais grossas a foliação é ausente, ou incipiente, tendendo a ser mais pronunciada ao longo do contato sul, onde há a incidência de zonas de deformação mais intensa, as quais são responsáveis pela brusca redução da granulação e forte orientação mineral no Granito Xinguara e, provavelmente, também nas encaixantes. A foliação nesta porção possui orientação geral WNW-ESE com mergulhos fortes $\left(>85^{\circ}\right)$.

GEOCRONOLOGIA POR EVAPORAÇÃO DE Pb EM MONOCRISTAIS DE ZIRCÃO As análises isotópicas, realizadas através do método de evaporação de $\mathrm{Pb}$ em monocristais de zircão, foram efetuadas no Laboratório de Geologia Isotópica do CG/UFPA. A metodologia utilizada nas análises foi àquela desenvolvida por Köber (1986). As análises foram feitas num espectrômetro de massa de ionização termal modelo FINNIGAN MAT 262. Por esse método, o zircão é analisado no estado sólido e as idades ${ }^{207} \mathrm{~Pb} / 206 \mathrm{~Pb}$ obtidas podem ser consideradas como 
idades mínimas ou como idades representativas da cristalização do mineral. Informações mais detalhadas sobre a aplicação desta metodologia encontram-se em Köber (1986) e Gaudette et al. (1998). Os resultados são apresentados com desvios de $2 \sigma$ e as correções do $\mathrm{Pb}$ comum são feitas mediante uso do modelo de evolução do $\mathrm{Pb}$ em estágio duplo proposto por Stacey \& Kramers (1975), utilizando a razão ${ }^{204} \mathrm{~Pb} /{ }^{206} \mathrm{~Pb}$ medida.

A separação cartográfica e petrográfica das unidades permitiu selecionar amostras representativas de cada corpo, de modo a determinar as suas idades e testar, por um método independente, a estratigrafia deduzida com base nas relações de campo e feições estruturais. Foram datadas as amostras AL-216, AL-163, AL-210C, MJL-09B, AL-60 e XN-34 (Fig. 2 ). As três primeiras correspondem a três pontos de amostragem do Tonalito Caracol, a quarta ao Trondhjemito Água Fria e as duas últimas a dois pontos de amostragem no Granito Xinguara. Além das idades obtidas com estas amostras também será discutida a idade obtida em quartzodiorito associado ao Granodiorito Rio Maria (AL-214), já apresentada por Dall'Agnol et al. (1999).

Procedimentos Analíticos e Tratamento dos Dados As amostras foram pulverizadas e peneiradas nas frações granulométricas de 250-170, 170-125, 125-60 e $<60 \mu \mathrm{m}$. As amostras com maior volume relativo foram tratadas inicialmente no elutriador, visando uma primeira concentração dos minerais pesados. Em seguida, os minerais ferromagnéticos foram extraídos com auxílio de um separador Frantz Isodynamic. Nessa etapa, o separador magnético foi ajustado para um ângulo de $25^{\circ}$ de inclinação longitudinal, $10^{\circ}$ de inclinação lateral e amperagem variando entre $0,5 \mathrm{e}$ 1,5A. Para a obtenção de um concentrado mais rico em zircão, a fração não magnética obtida no separador Frantz foi tratada com líquido pesado (bromofórmio) e, em seguida, os cristais de zircão foram selecionados por triagem manual sob lupa binocular. Os cristais selecionados para análise foram preferencialmente aqueles sem evidências de metamictização, sem inclusões ou fraturas. Entretanto, quando a quantidade desses cristais é insuficiente, foram analisados cristais com essas características. Por fim, os cristais selecionados foram aprisionados em filamentos de rênio, para subseqüente introdução no espectrômetro de massa.

A técnica analítica empregada no espectrômetro FINNIGAN MAT 262 utiliza dois filamentos posicionados frente a frente, sendo um filamento de evaporação, o qual contém um cristal de zircão, e um filamento de ionização, a partir do qual o $\mathrm{Pb}$ é analisado. $\mathrm{O}$ filamento de evaporação é aquecido gradativamente em temperaturas preestabelecidas, que constituem as etapas de evaporação. Normalmente são realizadas três etapas de evaporação $\left(1450^{\circ} \mathrm{C}, 1500^{\circ} \mathrm{C}\right.$ e $\left.1550^{\circ} \mathrm{C}\right)$. Mais raramente, dependendo da quantidade de $\mathrm{Pb}$ que o cristal contém, podem ser realizadas até cinco etapas de evaporação. Durante cada etapa de evaporação, que dura aproximadamente 5 minutos, ocorre a liberação do $\mathrm{Pb}$ do retículo cristalino do zircão. Esse $\mathrm{Pb}$ deposita-se imediatamente no filamento de ionização, o qual é mantido em temperatura ambiente. Em seguida, o filamento de evaporação é desligado e o filamento de ionização é aquecido a uma temperatura em torno de $1050^{\circ} \mathrm{C}$, quando o $\mathrm{Pb}$ ali depositado é ionizado. As intensidades das emissões dos diferentes isótopos de $\mathrm{Pb}$ podem ser medidas de duas formas: a primeira, para baixa intensidade de sinal, com monocoletor (um contador de ions), segundo uma varredura na seguinte seqüência de massas: 206, 207, 208, 206, 207 e 204. A segunda, para alta intensidade, é feita em multicoletor (contador de ions e caixas de Faraday), segundo uma varredura na seguinte sequiência de massas: 206, 207, 208 e 204. Em ambos os modos, cada conjunto de 10 varreduras define um bloco. Um bloco obtido no contador de ions fornece 18 razões ${ }^{207} \mathrm{~Pb} /{ }^{206} \mathrm{~Pb}$ e no multicoletor, 10 razões ${ }^{207} \mathrm{~Pb} /{ }^{206} \mathrm{~Pb}$. A partir das médias das razões ${ }^{207} \mathrm{~Pb} /{ }^{206} \mathrm{~Pb}$ dos blocos, define-se uma idade para cada etapa de evaporação.

Em cada etapa de evaporação são obtidos, em geral, até cinco blocos de dados nas análises em monocoletor e dez nas análises em multicoletor. A média das razões ${ }^{207} \mathrm{~Pb} /{ }^{206} \mathrm{~Pb}$ desses blocos define uma idade correspondente para cada etapa. Esses dados são representados em diagrama Idade (Ma) versus Etapas de evaporação. As idades obtidas nas diferentes etapas de evaporação podem apresentar diferentes valores, sendo que, normalmente, observa-se um aumento nas idades no sentido das etapas de mais alta temperatura. Quando isto ocorre, são consideradas apenas as idades obtidas nas temperaturas mais altas pois, neste caso, o $\mathrm{Pb}$ analisado é proveniente das porções do cristal de zircão com maior capacidade de retenção de $\mathrm{Pb}, \mathrm{e}$, portanto, as idades são teoricamente mais representativas daquelas de cristalização do mineral. Os dados obtidos são tratados estatisticamente segundo critérios metodológicos estabelecidos no laboratório.

Resultados Geocronológicos TONALITO CARACOL As amostras desta unidade geológica representam seus diferentes domínios estruturais: a amostra AL-216 é do domínio sul da área, onde se tem um bandamento de orientação WNW-ESE; a amostra AL-163 é do domínio SW, onde há a incidência de zonas de cisalhamento de baixo ângulo e a amostra AL-210C é do domínio NW, onde há registros de estruturas bandadas de direção N-S. Os pontos de coleta podem ser localizados na Fig. 2.

Os cristais de zircão destes biotita-tonalitos a trondhjemitos do Tonalito Caracol mostram uma coloração que varia de rosado a castanho claro, geralmente translúcidos a transparentes, com certo brilho adamantino, hábito prismático bipiramidal, multifacetados, com arestas retas e uniformes; alguns são zonados, sem inclusões e com poucas fraturas em seus núcleos. A Tabela 2 resume os resultados das análises isotópicas do $\mathrm{Pb}$ nos cristais de zircão das três amostras estudadas. Um conjunto de 5 cristais da amostra AL-216, forneceu idade de $2.948 \pm 5 \mathrm{Ma}(2 \sigma$, Fig. 3a); 6 cristais da amostras AL-163 forneceram idade de $2.936 \pm 3 \mathrm{Ma}(2 \sigma$, Fig. $3 \mathrm{~b}) \mathrm{e}$ 7 cristais da amostra AL-210C forneceram idade de $2.924 \pm 2 \mathrm{Ma}$ (20, Fig. 3c).

GRANODIORITO RIO MARIA Esta unidade já havia sido datada em sua região tipo, próximo da cidade de Rio Maria (Macambira 1992). Na região de Xinguara, a amostra coletada é de um corpo de quartzo-diorito relacionado ao Granodiorito Rio Maria que aparece no contato do Granodiorito Rio Maria e Tonalito Caracol, aproximadamente 3,5 km a sul de Xinguara, na margem leste da PA-150. A amostra AL-214, que corresponde a este quartzo-diorito, foi analisada por Dall' Agnol et al. (1999). Desta amostra os referidos autores selecionaram e dataram 5 cristais de zircão, os quais forneceram uma idade média de $2.878 \pm 4 \mathrm{Ma}$ (Fig. 4a).

TRONDHJEMITO ÁGUA FRIA Foi datada uma amostra do Trondhjemito Água Fria (MJL-09B), coletada a cerca de $1 \mathrm{~km}$ a sul de sua seção tipo, a $18 \mathrm{~km}$ a NE de Xinguara, na margem leste da PA-150 (Fig. 2). Trata-se de uma rocha de composição trondhjemítica, cuja estruturação principal é um marcante bandamento composicional de origem magmática, orientado na 
Tabela 2 - Resultados das análises dos cristais de zircão das amostras do Tonalito Caracol e do Granito Xinguara.

\begin{tabular}{|c|c|c|c|c|c|c|}
\hline \multicolumn{7}{|c|}{ AL-216 - Tonalito Caracol do domínio $S$} \\
\hline Zircão & $\begin{array}{c}\text { Razões Utiliz./ } \\
\text { Total }\end{array}$ & $\begin{array}{c}{ }^{204} \mathrm{~Pb}{ }^{206} \mathrm{~Pb} \\
\pm 2 \sigma\end{array}$ & $\begin{array}{c}{ }^{2018} \mathrm{~Pb}{ }^{206} \mathrm{~Pb} \\
\pm 2 \sigma\end{array}$ & $\begin{array}{c}{ }^{207} \mathrm{~Pb}{ }^{206} \mathrm{~Pb} \\
\pm 2 \sigma\end{array}$ & $\begin{array}{c}\left({ }^{207} \mathrm{~Pb} /^{206} \mathrm{~Pb}\right) c \\
\pm 2 \sigma\end{array}$ & $\begin{array}{l}\text { Idade } \\
(\mathrm{Ma})\end{array}$ \\
\hline AL-216/1 & 54 & $0,000078 \pm 7$ & $0,07507 \pm 79$ & $0,21733 \pm 33$ & $0,21646 \pm 36$ & $2.955 \pm 3$ \\
\hline AL-216/2 & 70 & $0,000073 \pm 33$ & $0,08575 \pm 39$ & $0,21745 \pm 54$ & $0,21663 \pm 85$ & $2.956 \pm 6$ \\
\hline AL-216/8 & 32 & $0,000080 \pm 18$ & $0,07241 \pm 157$ & $0,21652 \pm 122$ & $0,21564 \pm 99$ & $2.949 \pm 7$ \\
\hline AL-216/12 & 96 & $0,000027 \pm 1$ & $0,06340 \pm 44$ & $0,21554 \pm 49$ & $0,21522 \pm 49$ & $2.946 \pm 4$ \\
\hline AL-216/14 & 86 & $0,000075 \pm 3$ & $0,06676 \pm 44$ & $0,21582 \pm 29$ & $0,21496 \pm 28$ & $2.944 \pm 2$ \\
\hline Total & 338 & & & & Idade média & $2948 \pm 5$ \\
\hline \multicolumn{7}{|c|}{ AL-163 - Tonalito Caracol do domínio SW } \\
\hline AL-163/3 & 70 & $0,000027 \pm 2$ & $0,06453 \pm 189$ & $0,21371 \pm 26$ & $0,21339 \pm 26$ & $2.932 \pm 2$ \\
\hline AL-163/5 & 36 & $0,000050 \pm 15$ & $0,11646 \pm 50$ & $0,21416 \pm 60$ & $0,21356 \pm 61$ & $2.933 \pm 5$ \\
\hline AL-163/6 & 88 & $0,000026 \pm 2$ & $0,09041 \pm 21$ & $0,21366 \pm 28$ & $0,21335 \pm 28$ & $2.931 \pm 2$ \\
\hline AL-163/8 & 88 & $0,000022 \pm 4$ & $0,13762 \pm 41$ & $0,21441 \pm 35$ & $0,21417 \pm 35$ & $2.938 \pm 3$ \\
\hline \multirow[t]{2}{*}{ AL-163/9 } & 88 & $0,000028 \pm 3$ & $0,07747 \pm 33$ & $0,21520 \pm 29$ & $0,21481 \pm 28$ & $2.942 \pm 2$ \\
\hline & 14 & $0,000216 \pm 64$ & $0,09733 \pm 65$ & $0,21658 \pm 73$ & $0,21407 \pm 104$ & $2.937 \pm 8$ \\
\hline \multirow[t]{2}{*}{ ALF-163/11 } & 78 & $0,000032 \pm 1$ & $0,11406 \pm 41$ & $0,21455 \pm 31$ & $0,21417 \pm 31$ & $2.938 \pm 2$ \\
\hline & 462 & & & & Idade média & $2936 \pm 3$ \\
\hline \multicolumn{7}{|c|}{ AL-210C - Tonalito Caracol do domínio NW } \\
\hline AL-210/1 & 52 & $0,000012 \pm 6$ & $0,09159 \pm 53$ & $0,21247 \pm 48$ & $0,21230 \pm 49$ & $2.924 \pm 4$ \\
\hline AL-210/3 & 90 & $0,000021 \pm 3$ & $0,08830 \pm 25$ & $0,21315 \pm 31$ & $0,21290 \pm 32$ & $2.928 \pm 2$ \\
\hline \multirow[t]{3}{*}{ AL-210/5 } & 84 & $0,000030 \pm 2$ & $0,05583 \pm 75$ & $0,21282 \pm 27$ & $0,21246 \pm 27$ & $2.925 \pm 2$ \\
\hline & 84 & $0,000038 \pm 2$ & $0,06403 \pm 17$ & $0,21324 \pm 29$ & $0,21283 \pm 29$ & $2.928 \pm 2$ \\
\hline & 88 & $0,000002 \pm 1$ & $0,05897 \pm 28$ & $0,21314 \pm 34$ & $0,21310 \pm 34$ & $2.930 \pm 3$ \\
\hline AL-210/7 & 18 & $0,000049 \pm 10$ & $0,09046 \pm 66$ & $0,21322 \pm 88$ & $0,21265 \pm 88$ & $2,926 \pm 7$ \\
\hline AL-210/10 & 94 & $0,000026 \pm 1$ & $0,09653 \pm 21$ & $0,21259 \pm 17$ & $0,21229 \pm 17$ & $2.923 \pm 1$ \\
\hline \multirow[t]{3}{*}{ AL-210/14 } & 90 & $0,000030 \pm 3$ & $0,09144 \pm 34$ & $0,21225 \pm 25$ & $0,21188 \pm 25$ & $2.920 \pm 2$ \\
\hline & 93 & $0,000026 \pm 1$ & $0,08994 \pm 39$ & $0,21215 \pm 32$ & $0,21185 \pm 32$ & $2.920 \pm 2$ \\
\hline & 52 & $0,000040 \pm 3$ & $0,09662 \pm 55$ & $0,21254 \pm 44$ & $0,21207 \pm 46$ & $2.922 \pm 4$ \\
\hline \multirow[t]{2}{*}{ AL-210/15 } & 84 & $0,000038 \pm 4$ & $0,08583 \pm 21$ & $0,21287 \pm 25$ & $0,21239 \pm 25$ & $2.924 \pm 2$ \\
\hline & 88 & $0,000033 \pm 1$ & $0,08579 \pm 27$ & $0,21233 \pm 33$ & $0,21194 \pm 33$ & $2.921 \pm 2$ \\
\hline Total & 917 & & & & Idade média & $2924 \pm 2$ \\
\hline \multicolumn{7}{|c|}{ Amostras AL-60 e XN-34 - Granito Xinguara } \\
\hline \multirow[t]{2}{*}{ AL-60/6 } & 18 & $0,0000270 \pm 2$ & $0,118740 \pm 73$ & $0,204040 \pm 79$ & $0,20372 \pm 79$ & $2.856 \pm 6$ \\
\hline & 93 & $0,0000220 \pm 1$ & $0,119200 \pm 18$ & $0,204990 \pm 16$ & $0,20473 \pm 16$ & $2.865 \pm 1$ \\
\hline AL-60/8 & 96 & $0,0000190 \pm 1$ & $0,007840 \pm 10$ & $0,204960 \pm 16$ & $0,20473 \pm 16$ & $2.865 \pm 1$ \\
\hline \multirow[t]{2}{*}{$\mathrm{XN}-34 / 17$} & 84 & $0,0000610 \pm 3$ & $0,200120 \pm 55$ & $0,205820 \pm 26$ & $0,20503 \pm 26$ & $2.867 \pm 2$ \\
\hline & 57 & $0,0000670 \pm 2$ & $0,200850 \pm 70$ & $0,205720 \pm 37$ & $0,20492 \pm 37$ & $2.866 \pm 3$ \\
\hline Total & 348 & & & & Idade média & $2865 \pm 1$ \\
\hline
\end{tabular}

Tabela 3 - Resultados das análises dos cristais de zircão das amostras do Trondhjemito Água Fria.

\begin{tabular}{|c|c|c|c|c|c|}
\hline Zircão & ${ }^{204} \mathrm{~Pb}{ }^{206} \mathrm{~Pb}$ & ${ }^{207} \mathrm{~Pb}{ }^{206} \mathrm{~Pb}$ & $\left({ }^{207} \mathrm{~Pb} /^{206} \mathrm{~Pb}\right) \mathrm{c}$ & Idade $(M a) \#$ & Idade $(M a)^{*}$ \\
\hline Ml-09B/1 & $0,000128 \pm 0,000041$ & $0,203881 \pm 0,0006$ & $0,201318 \pm 0,00073$ & $2858 \pm 10$ & $2837 \pm 12$ \\
\hline $\mathrm{M} 1-09 \mathrm{~B} / 2$ & $0,000169 \pm 0,000024$ & $0,205139 \pm 0,002035$ & $0,201873 \pm 0,002053$ & $2871 \pm 32$ & $2845 \pm 32$ \\
\hline $\mathrm{MI}-09 \mathrm{~B} / 3$ & $0,000097 \pm 0,000015$ & $0,201704 \pm 0,000698$ & $0,199219 \pm 0,000745$ & $2841 \pm 11$ & $2821 \pm 12$ \\
\hline $\mathrm{Ml}-09 \mathrm{~B} / 5$ & $0,000032 \pm 0,000124$ & $0,214306 \pm 0,003603$ & $0,210756 \pm 0,004343$ & $2943 \pm 54$ & $2916 \pm 54$ \\
\hline M1-09B/7 & $0,000148 \pm 0,000022$ & $0,196399 \pm 0,001957$ & $0,194990 \pm 0,002004$ & $2800 \pm 33$ & $2788 \pm 34$ \\
\hline MI-09B/10 & $0,000248 \pm 0,000023$ & $0,210193 \pm 0,000583$ & $0,208269 \pm 0,000625$ & $2908 \pm 09$ & $2893 \pm 10$ \\
\hline \multirow[t]{2}{*}{$\mathrm{MI}-09 \mathrm{~B} / 13$} & $0,000045 \pm 0,000011$ & $0,206589 \pm 0,00038$ & $0,205923 \pm 0,000403$ & $2879 \pm 06$ & $2874 \pm 06$ \\
\hline & & & Idade média & & $2864 \pm 21$ \\
\hline
\end{tabular}

direção NW-SE a WNW-ESE. O seu aspecto textural primário encontra-se preservado. Dessa amostra foram analisados 7 cristais de zircão, os quais forneceram uma idade média de $2.864 \pm 21 \mathrm{Ma}$ (Tabela 3, Fig. 4b).

GRANITO XINGUARA Em virtude das dificuldades de se extrair cristais de zircão deste granito foram utilizadas duas amostras. A amostra AL-60 foi coletada a $4 \mathrm{~km}$ a NE da sede do município de Xinguara, enquanto a XN-34, a cerca de $10 \mathrm{~km}$ a norte da cidade (Fig. 2). As amostras representam leucomonzogranitos de granulação média e cor rosa claro. $\mathrm{O}$ granito possui uma foliação não penetrativa e macroscopicamente aparenta ser pouco a não deformado. Ao microscópico, o aspecto textural mais marcante é uma recristalização moderada a forte dos feldspatos e do quartzo.

A amostra AL-60 forneceu poucos cristais de zircão e destes, apenas 12 foram selecionados para análise. Os cristais analisados são em parte similares aos descritos nas amostras do Tonalito Caracol, diferindo dos mesmos por serem menores e por terem coloração castanha mais acentuada, refletindo certamente um maior grau de metamictização. As etapas de mais alta temperatura dos cristais selecionados mostraram uma idade de $2.865 \pm 1 \mathrm{Ma}$ (Tabela 2, Fig. 4c). Com objetivo de melhorar a confiabilidade da idade obtida para o Granito Xinguara foram analisados adicionalmente 5 cristais de zircão da amostra XN-34. Os cristais desta 

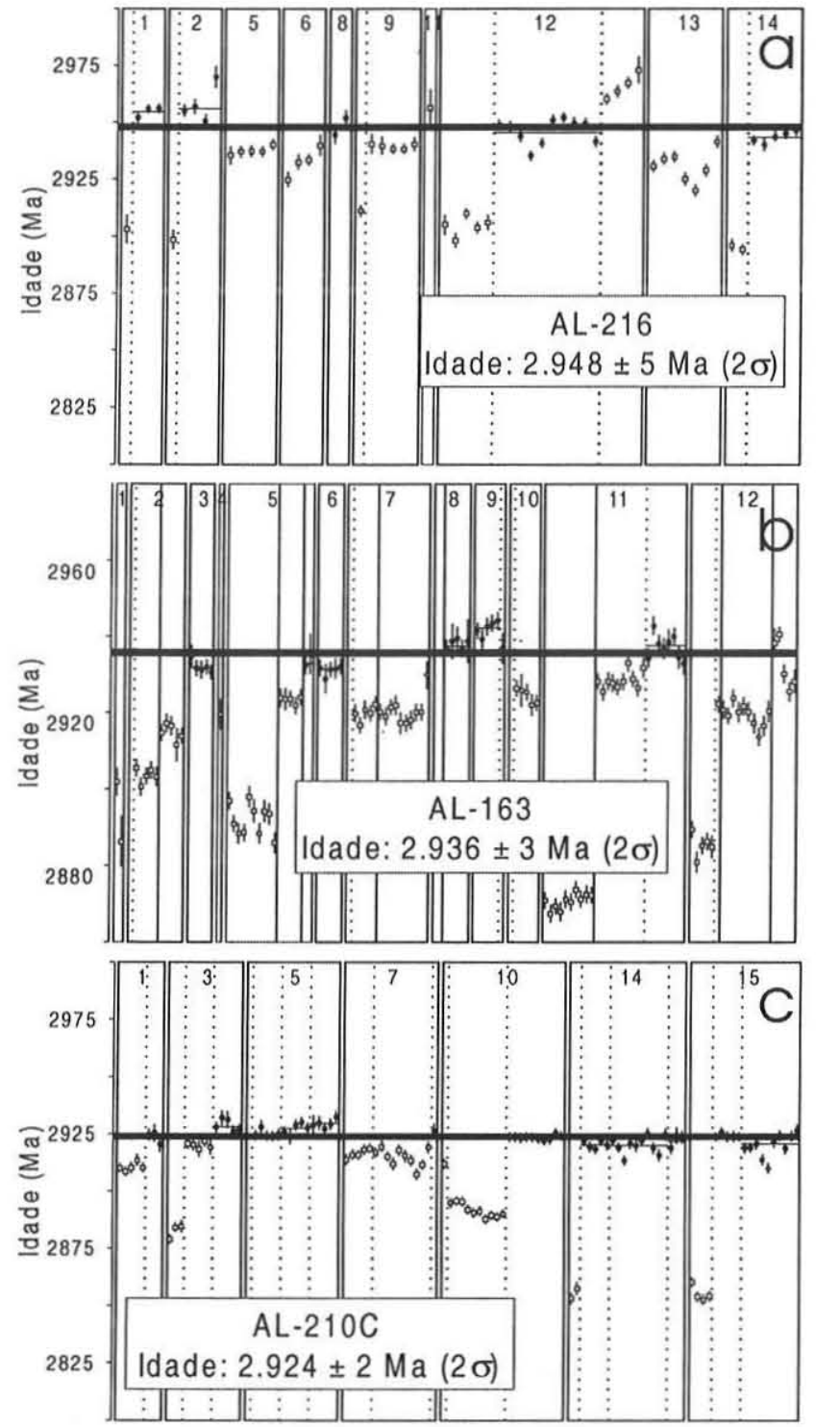

Etapas de evaporação

Figura 3 - Diagramas Idade vs. Etapas de evaporação de análises de cristais de zircão de amostras do Tonalito Caracol: (a) AL-216, (b) AL-163 e (c) AL-210C. Círculos cheios - bloco de razões isotópicas utilizadas para o cálculo da idade; quadrados vazados - bloco eliminado subjetivamente; desvio analítico $2 \sigma$.

amostra são morfologicamente similares aos da amostra AL-60, porém bem menores. As etapas de mais alta temperatura dos cristais 15 e 17 (Tabela 2) mostraram uma idade média de $2.866 \pm 2 \mathrm{Ma}$, idade com valor bem próximo daquela obtida para a amostra $\mathrm{AL}$ 60. O diagrama da Fig. 4c mostra os resultados das análises das duas amostras. Os cristais 6 e 8 (AL-60) e 15 e 17 (XN-34) definem uma idade média de $2.865 \pm 1 \mathrm{Ma}$ (Fig. 4c). Na amostra AL-60, as etapas de mais alta temperatura dos cristais 4, 5 e 10 forneceram uma idade bem maior de $2.928 \pm 2 \mathrm{Ma}$ (Fig. 4d) e mostram que certos cristais do Granito Xinguara possuem uma história um pouco mais complexa, como adiante discutido.

DISCUSSÃO E INTERPRETAÇÃO DOS RESULTADOS Os dados geocronológicos obtidos pelo método de evaporação de $\mathrm{Pbem}$ monocristais de zircão ( $\mathrm{Pb}-\mathrm{Pb}$ em zircão) fornecem, em geral, valores similares às idades fornecidas pelo método U-Pb em zircão (Andsdell \& Kyser 1991, Macambira \& Lafon 1995, Dall'Agnol et al. 1999). A rigor, as idades $\mathrm{Pb}-\mathrm{Pb}$ em zircão devem ser consideradas como "idades mínimas" de cristalização dos zircões analisados. Porém, na região de Rio Maria e em outras áreas do Cráton Amazônico, as idades obtidas pelo método U-Pb em zircão (Machado et al. 1991, Macambira 1992, Pimentel \& Machado 1994) se superpõem aos valores fornecidos pelo método de evaporação de $\mathrm{Pb}$ em zircão. Desta forma, acredita-se que as idades obtidas pelo método $\mathrm{Pb}-\mathrm{Pb}$ por evaporação de zircão podem ser perfeitamente interpretadas como indicativas das idades de cristalização dos zircões na área em foco.

Com base nas informações acima, pode-se considerar que as idades obtidas pelo método de evaporação de $\mathrm{Pb}$ em monocristais de zircão, para os granitóides da região de Xinguara, correspondem às idades de cristalização dos cristais analisados e, conseqüentemente, excetuando o caso de possíveis zircões herdados ou xenocristais, às idades de colocação das rochas que os contêm. As idades obtidas estão sumarizadas na Tabela 4. Estes dados são coerentes, em linhas gerais, com a ordem de colocação dos corpos a partir de relações estratigráficas e feições estruturais observadas em campo.

Todos os cristais de zircão analisados das amostras do Tonalito Caracol foram considerados como de origem magmática e as idades obtidas seriam, seguindo o raciocínio exposto acima, consideradas como idades de cristalização e, conseqüentemente, de colocação das rochas que os contêm. Entretanto, idades obtidas nos diferentes domínios do Tonalito Caracol (2.948 $\pm 5 \mathrm{Ma}$ - AL-216, $2.936 \pm 3 \mathrm{Ma}-\mathrm{AL}-163 \mathrm{e} 2.924 \pm 2 \mathrm{Ma}-\mathrm{AL}-210 \mathrm{C}$ ), mostram diferenças expressivas, pois não se superpõem, quando se consideram os erros analíticos, que são muito baixos. Isto não é facilmente explicável, pois não se dispõe de evidências conclusivas que justifiquem a separação dessas rochas. Uma hipótese plausível seria a de que este tonalito foi formado por intrusões que se sucederam em um tempo relativamente curto (2.948 a $2.924 \mathrm{Ma})$, mas com diferenças ainda detectáveis pela método utilizado. Neste caso, o Tonalito Caracol não corresponderia a uma, mas várias intrusões, não rigorosamente sincrônicas, que posteriormente seriam afetadas por deformação coaxial e justapostas. Uma outra hipótese seria admitir que as idades obtidas em uma ou mais das amostras datadas não correspondem rigorosamente às idades de cristalização, sendo de fato idades mínimas, muito próximas das idades de cristalização, resultante de perdas parciais de $\mathrm{Pb}$ radiogênico. Esta possibilidade tem como base os sinais de metamictização observados em alguns dos cristais analisados.

A idade obtida na amostra AL-216 do Tonalito Caracol de $2.948 \pm 5 \mathrm{Ma}$, se superpõe, dentro do erro, com a idade de cristalização e colocação obtida para o Tonalito Arco Verde $(2.957$ +/-25 Ma, U-Pb em zircão, Macambira 1992). Ela é um pouco inferior à idade dos gnaisses Tonalitos do Complexo Xingu na região de São Félix do Xingu ( $2.972 \pm 16 \mathrm{Ma}$, Avelar et al. 1999). Isto sugere que a cristalização e colocação do Tonalito Caracol na região de Xinguara foi concomitante com a do Tonalito Arco Verde e, que a colocação dos granitóides TTG na região de São Félix do Xingu poderia ter se dado um pouco mais cedo. Por fim, vale ressaltar que estas idades ratificam a existência de um intenso magmatismo TTG Arqueano no Terreno Granito-Greenstone de Rio Maria no período de 2.979 a 2.924 Ga (p. ex. Pimentel \& Machado 1994, Macambira \& Lafon 1995, Macambira \& Lancelot 1996, Dall'Agnol 


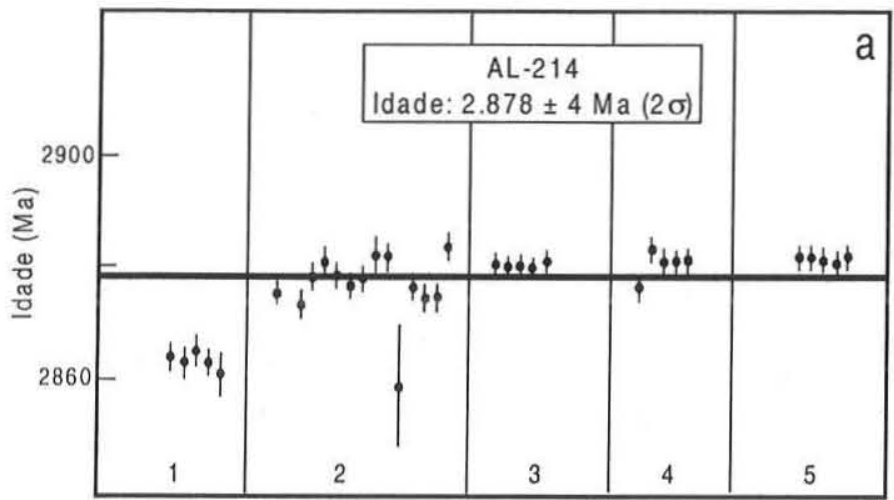

Etapas de evaporaçăo

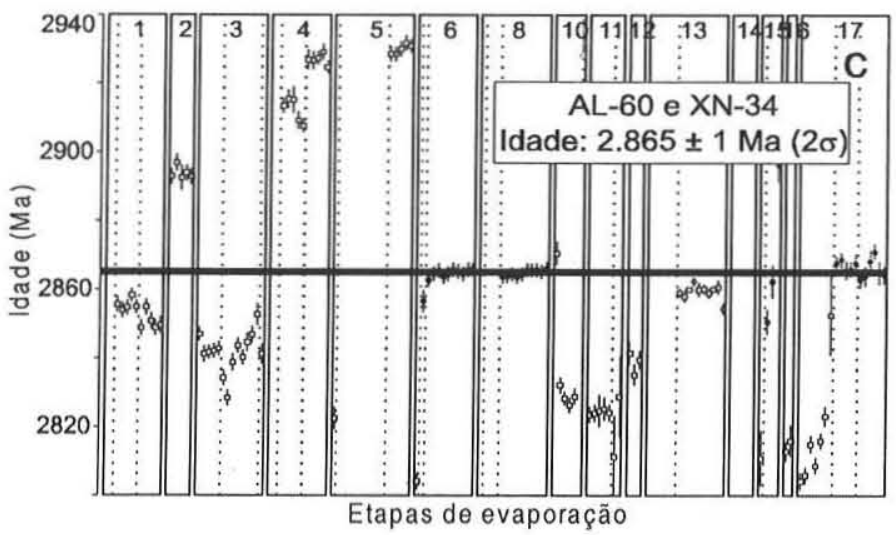

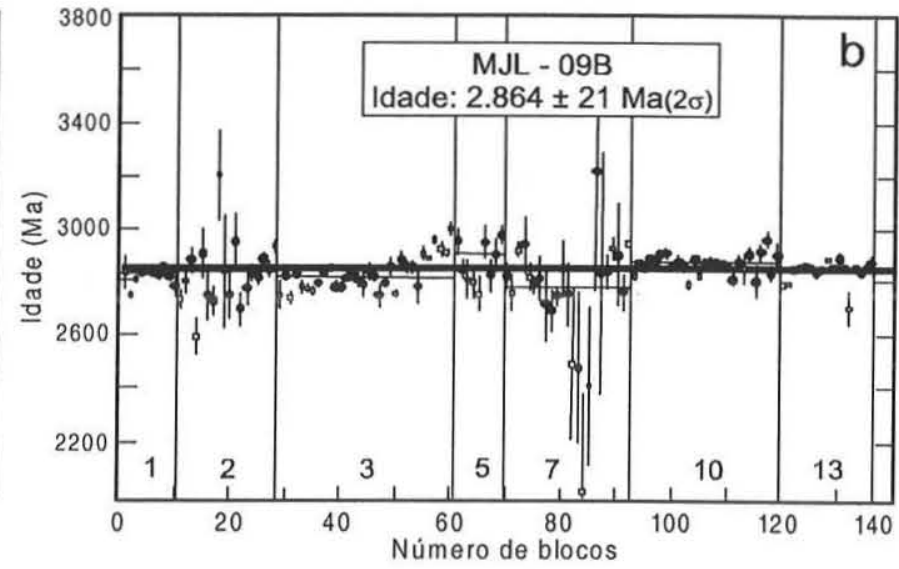

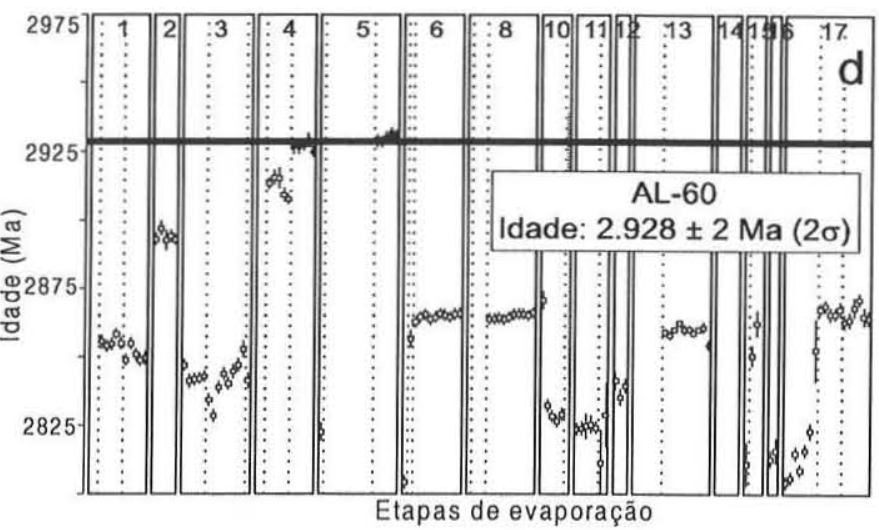

Figura 4 - Diagrama Idade vs. Etapas de evaporação dos cristais de zircão do: (a) Granodiorito Rio Maria, (b) Trondhjemito Água Fria, (c) e (d) Granito Xinguara. Símbolos como na Fig. 3.

Tabela 4 - Síntese das idades de rochas granitóides da região de Xinguara.

\begin{tabular}{lccc}
\hline \multicolumn{1}{c}{ Amostra } & Unidade Geológica & $N^{o}$ de grãos & Idade $(\mathrm{Ma})$ \\
\hline AL-216 & Tonalito Caracol - domínio S & 5 & $2.948 \pm 5$ \\
AL-163 & Tonalito Caracol - domínio SW & 6 & $2.936 \pm 3$ \\
AL-210C & Tonalito Caracol - domínio NW & 7 & $2.924 \pm 2$ \\
AL-214 & Quartzo-diorito Rio Maria & 5 & $2.878 \pm 4$ \\
MJL-09B & Trondhjemito Água Fria & 7 & $2.864 \pm 21$ \\
AL-60 + XN-34 & Granito Xinguara & 4 & $2.865 \pm 1$ \\
\hline
\end{tabular}

et al. 1997, Avelar et al. 1999, Althoff et al. 2000, Leite et al. 2001).

A idade de $2.936 \pm 3$ Ma obtida para a amostra AL-163, pode ser admitida como sendo de cristalização e colocação do Tonalito Caracol no domínio SW da área. Como a deformação imposta a esta rocha foi processada depois de sua completa cristalização e a instalação das zonas de cisalhamento foi anterior à colocação do Granito Xinguara, como discutido por Leite (2001) e Leite et al (2001), pode-se inferir que a instalação das referidas zonas deu-se no intervalo de tempo entre $2.936 \mathrm{Ma} \mathrm{e} 2.865 \mathrm{Ma}$ (idade de cristalização e colocação do Granito Xinguara). A presença destas zonas de cisalhamento poderia ser um indicativo de uma mudança no regime tectônico regional de vertical para horizontal.

O Granodiorito Rio Maria possui idade de cristalização e colocação de 2.874 +9/-10 Ma (U-Pb em zircão, Macambira 1992). Esta idade foi posteriormente confirmada por Pimentel \& Machado (1994) (Tabela 1). Na área em estudo, Dall'Agnol et al. (1999) obti- veram em uma amostra de quartzo-diorito associado ao Granodiorito Rio Maria uma idade $\mathrm{Pb}-\mathrm{Pb}$ em zircão de $2.878 \pm 4$ Ma, considerada como de cristalização e colocação. Vale salientar que $\mathrm{a}$ idade obtida por eles é similar às demais obtidas para o Granodiorito Rio Maria, o que confirma que o quartzo-diorito e o Granodiorito Rio Maria são contemporâneos.

O Trondhjemito Água Fria mostrou idade de cristalização e colocação de $2.864 \pm 21 \mathrm{Ma}$, similar à obtida para a cristalização e colocação do Granito Xinguara de $2.865 \pm 1 \mathrm{Ma}$. Estas idades são perfeitamente compatíveis com a ordem de colocação dos corpos proposta a partir das relações de campo, discutidas anteriormente, que indicam que estas rochas são contemporâneas e intrusivas no Tonalito Caracol.É importante ressaltar que, num intervalo de tempo muito curto de cerca de $15 \mathrm{Ma}$, a região de Rio Maria foi palco de intensa atividade magmática, ocorrendo um magmatismo de afinidade cálcico-alcalina rico em $\mathrm{Mg}$, seguido de um 
magmatismo trondhjemítico TTG mais jovem do que o Tonalito Caracol e de um magma granítico cálcio-alcalino fortemente fracionado.

A idade do Trondhjemito Água Fria é similar às idades obtidas por Pimentel \& Machado (1994) para o Trondhjemito Mogno e o Tonalito Parazônia (Tabela 1). A idade do Granito Xinguara também é similar às obtidas para o Granito Mata Surrão (2.872 $\pm 10 \mathrm{Ma}$, $\mathrm{Pb}-\mathrm{Pb}$ em rocha total, Rodrigues et al. $1992 ; 2.871 \pm 7 \mathrm{Ma}, \mathrm{Pb}-\mathrm{Pb}$ em zircão, Althoff et al. 2000). A semelhança de idades entre estes granitos sugere que ambos se relacionam a um mesmo evento regional. O mesmo indicaria a estabilização tectônica do Terreno Granito-Greenstone de Rio Maria ainda antes do final do Arqueano, o que não é comum em outros crátons arqueanos, como Pilbara (Austrália), Dharwar (India) e Kaapvaal (África) (Ridley 1992, Sylvester 1994).

A idade de $2.928 \pm 2 \mathrm{Ma}$, encontrada em alguns cristais de zircão da amostra AL-60 do Granito Xinguara, está bem próxima da obtida para o Tonalito Caracol no domínio NW da área (AL-210C), o que leva a concluir que se trata possivelmente de cristais herdados daquele tonalito. Isto sugere que o Tonalito Caracol possa ter servido de fonte do magma que originou o Granito Xinguara (Leite 2001, Leite et al. 2001).

\section{CONCLUSÕES E CONSIDERAÇÕES FINAIS Sobre a} Estratigrafia da Região de Xinguara A partir da integração dos dados geológicos, estruturais e geocronológicos, é possível consolidar uma proposta de estratigrafia para a região de Xinguara, limitada a norte pelo Greenstone Belts de Sapucaia (Oliveira et al. 1995) e a sul pelo Greenstone Belts de Identidade (Souza et al. 2001). Enclaves e mega-enclaves de greenstone ocorrem no Tonalito Caracol, indicando que a colocação dos tonalitos deste complexo foi posterior à formação dos greenstone belts. O Tonalito Caracol é o granitóide Arqueano mais antigo da região de Xinguara, pois é cortado pelos demais granitóides. Ele gerou idades que variam de $2.948 \pm 5$ a $2.924 \pm 2$ Ma.

Após um período de cerca de 50 Ma sem registro de formação de rochas, deu-se a intrusão do Granodiorito Rio Maria. Huhn et al. (1988) e Souza et al. (1990) relatam a presença de enclaves de greenstone no granodiorito, bem como evidências de metamorfismo de contato nos greenstone belts causados pela intrusão do Granodiorito Rio Maria. As idades coincidentes obtidas para esta unidade por diferentes métodos (ca. $2.87 \mathrm{Ga}$ ) também atestam que a sua formação foi posterior a dos greenstone belts $\mathrm{e}$ do Tonalito Caracol.

Cerca de 10-12 Ma após a colocação do Granodiorito Rio Maria, houve a colocação do Trondhjemito Água Fria e do Granito Xinguara. Estes últimos são intrusivos nos greenstone belts, no Tonalito Caracol e no Granodiorito Rio Maria, como atestam as relações de campo, inclusive enclaves destas unidades que são encontrados com certa freqüência dentro do Trondhjemito Água Fria e do Granito Xinguara. As idades obtidas para estas duas unidades $(2.86 \mathrm{Ga})$ confirmam sua relação de contemporaneidade, já evidenciada pelos dados estruturais.
Finalmente, decorridos aproximadamente $1,0 \mathrm{Ga}$, já no final do Paleoproterozóico, houve a intrusão de corpos graníticos anorogênicos, que na região de Xinguara são representados pelo Granito Manda Saia. Diques máficos e félsicos, contemporâneos deste magmatismo (Rivalenti et al. 1998, Silva Jr. et al. 1999), cortam todas as unidades anteriormente citadas.

Sobre a Tectônica Arqueana de Xinguara As relações de campo e os dados isotópicos $\mathrm{Pb}-\mathrm{Pb}$ por evaporação de zircão indicam dois períodos importantes de atividade tectônica e formação de rochas granitóides arqueanas na região de Xinguara: (i) $2.948 \pm 5$ a $2.924 \pm 2$ Ma: geração, colocação e deformação do Tonalito Caracol, correlacionado ao Tonalito Arco Verde e aos granitóides TTG da região de São Félix do Xingu. As idades obtidas confirmam um intenso magmatismo TTG Arqueano no Terreno GranitoGreenstone de Rio Maria no período de 2,97 a 2,92 Ga; (ii) $2.878 \pm$ 4 a $2.865 \pm 1$ Ma, geração, colocação e deformação em um curto período de tempo (10-15 Ma) do Granodiorito Rio Maria, Trondhjemito Água Fria e do Granito Xinguara, cerca de $50 \mathrm{Ma}$ após a formação dos últimos granitóides TTG.

$\mathrm{O}$ mais antigo destes períodos $(>2,95 \mathrm{a} 2,91 \mathrm{Ga})$ mostra várias analogias com a evolução dos crátons Pilbara (Autrália) e Dharwar (Índia) (Choukroune et al. 1997). Neste período foi formado um terreno a base de domos TTG e bacias greenstone belts, associado com um tectônica dominantemente vertical. Na segunda (a partir de 2,88 Ga) vários granitóides geneticamente diferentes formaram-se em um curto espaço de tempo, indicando mudanças nos processos de formação da crosta continental. Incluem-se aí leucogranitos de derivação crustal, os quais marcam a estabilização crustal do Terreno Granito-Greenstone de Rio Maria a 2,86 $\mathrm{Ga}$, bem antes do final do Arqueano, ao contrário do que se verifica em outros crátons. Neste estágio dar-se-ia o espessamento e estabilização da crosta, que se tornaria mais rígida. A partir daí o processo de convergência e subducção de placas seria mais efetivo. Neste contexto, poderia haver a fusão de um manto enriquecido em elementos incompatíveis que geraria o magma parental do Granodiorito Rio Maria. A fusão da crosta oceânica subductante, transformada em granada-anfibolito, geraria o magma dos granitóides TTG mais jovens . A fusão em diferentes graus dos granitóides TTG localizados na base da crosta poderia gerar os magmas graníticos do pluton Xinguara.

Agradecimentos Aos pesquisadores do Grupo de Pesquisa Petrologia de Granitóides (GPPG-CG-UFPa) em especial aos geó$\operatorname{logos}$ C. N. Lamarão e H. T. Costi, pelo apoio nas diversas etapas deste trabalho. Ao Prof. Thomas Scheller, a geóloga Cléris R. Sachett e ao estudante J. C. Melo pelo apoio nas etapas de preparação das amostras, obtenção e tratamento dos dados isotópicos. Este trabalho recebeu o apoio financeiro de $\mathrm{CNPq}(000400038 / 99 \mathrm{e}$ 463196/00-7), CAPES (bolsa de doutorado para o primeiro autor) e PROINT/UFPA. Este trabalho é uma contribuição ao PRONEX/ $\mathrm{CNPq}$ (Projeto 103/98 - Proc. 66.2103/1998-0). Aos revisores da RBG pelas sugestões ao manuscrito.

\section{Referências}

Andsdell K.M. \& Kyser T.K. 1991. Plutonism, deformation and metamorfism in Proterozoic Flin Flon Greenstone belt Canadá. Limits on timing by the zircon $\mathrm{Pb}$ evaporation technique. Geology, 18(5):518-521.
Althoff F.J., Barbey P., Boullier A.M., Dall'Agnol R. 1995. Composição e estrutura dos granitóides arqueanos da região de Marajoara. Bol. Mus. Paraense Emílio Goeldi, Série Ciências da Terra, 7:5-26. 
Althoff F.J., Barbey P., Boullier A.M. 2000. 2.8-3.0 Ga plutonism and deformation in the SE Amazonian craton: the Archean granitoids of Marajoara (Carajás Mineral province, Brazil). Prec. Res., 104:187-206.

Araújo O.J.B., Macambira E.M.B., Vale A.G., Oliveira J.R., Silva Neto C.S., Costa E.J.S., Santos A., Pena Filho J.I.C., Neves A.P., Jorge João X.S., Costa J.B.S. 1994. Primeira integração das investigações geológicas do Programa Grande Carajás na região SSE do Estado do Pará. In: SBG, Simp. Geol. Amaz., 4, Bol. Resumos, p. 299-301.

Araújo O.J.B. \& Maia R.G.N. 1991. Programa de levantamentos geológicos básicos do Brasil, Serra dos Carajás, folha SB-22-Z-A, Estado do Pará. Texto explicativo, Brasília, DNPM/CPRM. 164 p.

Avelar V.G., Lafon J.M., Correia Jr. F.C., Macambira E.M.B. 1999. O magmatismo arqueano da região de Tucumã-Província Mineral de Carajás: Novos dados geocronológicos. Rev. Bras. Geoc., 29:453460.

Barros C.E.M., Dall'Agnol R., Barbey P., Boullier A.M. 1997. Geochemistry of the Estrela Granite Complex, Carajás region, Brazil: an example of an Archean A-type granitoid. J. South Amer. Earth Sci., 10(3-4):321-330.

Barros C.E.M., Dall'Agnol R., Lafon J.-M., Teixeira N.P., Ribeiro J. W. 1992. Geologia e geocronologia Rb-Sr do Gnaisse Estrela, Curionópolis, PA. Bol. Mus. Par. Emílio Goeldi, série Ciências da Terra, 4:85-104.

Barros C.E.M., Sardinha A.S., Barbosa J.P.O., Krimski R., Macambira M.J.B. 2001. $\mathrm{Pb}-\mathrm{Pb}$ and $\mathrm{U}-\mathrm{Pb}$ zircon ages of Archean syntectonic granites of the Carajás Metallogenetic Province, Northern Brazil. In: Simp. Sulamer. Geol. Isotópica, 3, Pucón, Chile, Extended Abstracts Volume, pp.: 94-97.

Choukroune P., Ludden J.N., Chardon D., Calvert A.J., Bouhallier H. 1997. Archean crustal growth and tectonics processes: a comparison of the Superior Province, Canada and the Dharwar Craton, India. In: J.P. Burg \& M. Ford (Eds.), Orogeny Through Time. Geological Society Special Publication, London, 121:63-98.

Costa J.B.S., Araújo O.J.B., Santos A., Jorge João X.S., Macambira M.J.B., Lafon J.M. 1995. A província mineral de Carajás: aspectos tectono-estruturais, estratigráficos e geocronológicos. Bol. Mus. Par: Emílio Goeldi, Série Ciências da Terra, 7:199-235.

Dall'Agnol R., Rämö O.T., Magalhães M.S., Macambira M.J.B. 1999 Petrology of the Anorogenic, Oxidised Jamon and Musa Granites, Amazonian Craton: implications for the Genesis of Proterozoic AType Granites. Lithos, 46:431-462.

Dall'Agnol R., Lafon J.M., Macambira M.J.B. 1994. Proterozoic anorogenic magmatism in the Central Amazonian Province, Amazonian Craton: geochronological, petrological and geochemical aspects. Min. and Petrol., 50(1/3):113-138.

Dall'Agnol R., Souza, Z.S., Althoff F.J., Barros C.E.M., Leite A.A.S., Jorge João X.S. 1997. General aspects of the granitogenesis of the Carajás metallogenic province. In: Intern. Symp. Granites and Assoc. Miner., Excursion Guide, Salvador, 2:135-161.

Dias G.S., Macambira M.J.B., Dall'Agnol R., Soares A.D.V., Barros C.E.M. 1996. Datação de zircões de sill de metagabros: comprovação da idade arqueana da Formação Águas Claras, Carajás-Pará. In: SBG, Simp. Geol. Amaz., Belém. Boletim Resumo, 5:376-379.

Docegeo (Rio Doce Geologia e Mineração - Distrito Amazônia) 1988. Revisão litoestratigráfica da Província Mineral de Carajás, Pará. In: SBG, Cong. Bras. Geol., 35. Anexos, vol. Província Mineral de Carajás - Litoestratigrafia e Principais Depósitos Minerais, p. 11-54.

Gaudette H.E., Lafon J.M., Macambira M.J.B., Moura C.A.V., Scheller T. 1998. Comparison of single filament $\mathrm{Pb}$ evaporation/ionization zircon ages with conventional $\mathrm{U}-\mathrm{Pb}$ results: examples from Precambrian of Brazil. J. South Amer. Ear. Sci, 11(4):351-363.

Gibbs A.K., Wirth K.R., Hirata W.K., Olszewski W.J. 1986. Age and composition of the Grão Para Group Volcanics, Serra dos Carajás. Rev. Bras. Geoc., 16(2):201-211.

Huhn S.R.B., Santos A.B.S., Amaral A.F., Ledsham E.J., Gouveia J.L., Martins L.B.P., Montalvão R.M.G., Costa V.G. 1988. O terreno granito-greenstone da região de Rio Maria, sul do Pará. In: SBG, Cong. Bras. Geol., 35. Anais. 3:1438-1453.

Huhn S.B., Macambira M.J.B., Dall'Agnol R. 1999. Geologia e geocronologia $\mathrm{Pb}-\mathrm{Pb}$ do Granito Alcalino Planalto, Região da Serra do Rabo, Carajás-PA. In: SBG, Simp. Geol. Amaz., 6, Boletim de Resumos, p. 463-466.

Kober B. 1986. Whole-grain evaporation for ${ }^{207} \mathrm{~Pb} /{ }^{206} \mathrm{~Pb}$-ageinvestigations on single zircons using a double-filament thermal ion source. Contrib. Mineral. Petrol., 93:482-490.

Lafon J.M., Rodrigues E., Duarte K.D. 1994. Le granite Mata Surrão: un magmatisme monzogranitique contemporain des associations tonalitiques-trondhjemitiques-granodioritiques archéennes de la région de Rio Maria (Amazonie Orientale, Brésil). Comptes Rendues de la Academie de Sciences de Paris, t. 318, serie II, p. 642- 649.

Leite A.A.S. 2001. Geoquímica, petrogênese e evolução estrutural dos granitóides arqueanos da região de Xinguara, SE do Cráton Amazônico. Tese de Doutorado, Centro de Geociências, Universidade Federal do Pará, Belém, 330p.

Leite A.A.S., Althoff F.J., Dall'Agnol R., Macambira M.J.B., Rämö O.T., Vale A.V. 2001. Arcabouço estrutural, geocronologia e petrogênese dos granitóides arqueanos de Xinguara-PA: implicações para a evolução geológica do Terreno Granito-Greenstone de Rio Maria, SE do estado do Pará. In: SBG, Simp. Geol. Amaz., 7, Resumo, CD-rom.

Leite A.A.S. \& Dall'Agnol R. 1997. Geologia e petrografia do maciço granítico Arqueano Xinguara e de suas encaixantes - SE do Pará. Bol. do Mus. Par. Emílio Goeldi, Série Ciências da Terra, 9:43-81.

Leite A.A.S., Dall'Agnol R., Althoff F.J. 1999. Geoquímica e aspectos petrogenéticos do Granito Xinguara, Terreno GranitoGreenstone de Rio Maria-Cráton Amazônico. Rev. Bras. Geoc., 23:429-436.

Lindenmayer Z.G., Fyfe W.S., Bocalon V.L.S. 1994. Nota preliminar sobre as intrusões granitóides do depósito de cobre do Salobo, Carajás. Acta Geol. Leopold., 17(40): 153-184.

Macambira M.J.B. 1992. Chronologie U-Pb, Rb/Sr, K/Ar et croissance de la croûte continentale dans L'Amazonie du sud-est; exemple de la région de Rio Maria, Province de Carajas, Brésil. Dissertação de doutorado, Université Montpellier II - France, 212 p

Macambira M.J.B. \& Lafon J.M. 1995. Geocronologia da Província Mineral de Carajás; síntese dos dados e novos desafios. Boletim do Mus. Par. Emílio Goeldi, série Ciências da Terra, 7:263-288.

Macambira M.J.B. \& Lancelot J.R. 1996. Time constraints for the formation of the Archean Rio Maria crust, southeastern Amazonian Craton, Brazil. Inter. Geol. Rev, 38:1134-1142.

Machado N., Lindenmayer Z., Krogh T.E., Lindenmayer D. 1991. U-Pb geochronology of Archean magmatism and basement reactivation in the Carajás Area, Amazon Shield, Brazil. Prec. Res., 49:329-354.

Medeiros H. \& Dall'Agnol R. 1988. Petrologia da porção leste do Batólito Granodiorítico Rio Maria, sudeste do Pará. In: SBG, Congr. Bras. Geol., 35. Anais, 3:1488-1499.

Oliveira C.G., Santos R.V., Leonardos O.H. 1995. Geologia e minera- 
Geologia e geocronologia dos granitóides arqueanos da regiāo de Xinguara (PA) e suas implicaçōes na evolução do terreno granitogreenstone de Rio Maria, Cráton Amazônico

lizações auríferas do greenstone belt de Sapucaia, sudeste do Pará. Bol. Mus. Par: Emílio Goeldi, Série Ciências da Terra, 7:61-91.

Pidgeon R.T., Macambira M.J.B., Lafon J.M. 2000. Th-U-Pb isotopic systems and internal structures of complex zircons from an enderbite for the ages of granulite facies metamorphism and the protolith of the enderbite. Chem. Geol., 166:159-171.

Pimentel M.M. \& Machado N. 1994. Geocronologia U-Pb dos terrenos granito-greenstone de Rio Maria, Pará. In: SBG, Cong. Bras. Geol., 38. Boletim de Resumos p. 390-391.

Ridley J.R. 1992. The termal causes and effects of voluminous, late Archaen: terrains, processes and metallogeny. Geology Dept. \& University Extension, The University of Western Australia Publications, 22:275-285.

Rivalenti G., Mazzuchelli M., Girardi V.A.V., Cavazzini G., Finatti C., Barbieri M.A., Teixeira W. 1998. Petrogenesis of the Paleoproterozoic basalt-andesite-rhyolite dyke association in the Carajás region, Amazonian craton. Lithos, 43:235-265.

Rodrigues E.M.S., Lafon J.M., Scheller T. 1992. Geocronologia Pb-Pb em rochas totais da Província Mineral de Carajás: primeiros resultados. In: SBG, Congr. Bras. Geol., 37., São Paulo. Boletim de Resumo, 2:183-184.

Silva Jr. R.O, Dall'Agnol R., Oliveira E.P. 1999. Geologia, petrografia e geoquímica dos diques proterozóicos da região de Rio Maria, sudeste do Pará. Geoch. Brasiliensis, 13(2):163-181.

Souza S.R.B., Macambira M.J.B., Horbe M.A. 1995. Geochronological and isotopic evidences of the influence of the Paleoproterozoic Pojuca Granite on the $\mathrm{Cu}-\mathrm{Zn}$ (Au-Mo-Ag) deposit, Carajas province, Brazil. In: Symp. Rapakivi Gran. Rel. Rocks. University Federal of Para.
Center for Geociences, Abstract. p. 76.

SouzaZ.S. 1994. Geologia e petrogênese do "Greenstone Belt" Identidade: implicações sobre a evolução geodinâmica do terreno granito"greenstone" de Rio Maria, SE do Pará. Dissertação de Doutorado Universidade Federal do Pará, Centro de Geociências, 624p.

Souza S.Z., Dall'Agnol R., Althoff F.J., Leite A.A.S., Barros C.E.M. 1996. Carajás mineral province: geological, geochronological and tectonic constrasts on the Archean evolution of the Rio Maria GraniteGreenstone Terrain and the Carajás block. In: SBG, Symp. Arch. Terr. South Amer. Platf., Extended abstracts, p 31-32.

Souza Z.S., Medeiros H., Althoff F.J., Dall'Agnol R. 1990. Geologia do terreno granito-greenstone Arqueano da região de Rio Maria, sudeste do Pará. In: SBG, Congr. Bras. Geol., 36. Anais, 6:2913-2928.

Souza Z.S., Potrel H., Lafon J.M., Althoff F.J., Pimentel M.M., Dall'Agnol R., Oliveira C.G. 2001. Nd, $\mathrm{Pb}$ and $\mathrm{Sr}$ isotopes of the Identidade Belt, an Archaean greenstone belt of the Rio Maria region (Carajas Province, Brazil): implications for the Archaean geodynamic evolution of the Amazonian Craton. Prec. Res. 109(3-4):293-315.

Sylvester P.J. 1994. Archean granite plutons. In: K.C. Condie (ed.) Archean crustal evolution. Developments in Precambrian Geology 11 , pp. 261-314

Stacey J.S. \& Kramers J.D. 1975. A proximation of terrestrial lead isotope evolution by a two stage model. Ear. Planet. Sci. Lett., 26:207-221.

Manuscrito A-1374

Recebido em 25 de setembro de 2002

Revisão dos autores em 18 de setembro de 2004 Revisão aceita em 20 de setembro de 2004 